\title{
Effects of an Increase in Prescription Copayment on Utilization of Low-Sedating Antihistamines and Nasal Steroids
}

BRIAN L. MEISSNER, PharmD; W. MARK MOORE, PharmD, MBA;

JUDITH A. SHINOGLE, PhD, MSc; C.E. REEDER, PhD; and JOHN M. LITTLE, JR., MD

\begin{abstract}
BACKGROUND: Health plans are using 3-tier copayment designs and other methods to control utilization that shifts drug costs to plan members. There is a need to determine the effects of increased member cost sharing on drug utilization and drug costs.
\end{abstract}

OBJECTIVE: To assess the impact of a $\$ 10$ increase in prescription copayment in a public employer health plan for 2 classes of drugs used for allergic rhinitis.

METHODS: Changes in the number of prescriptions dispensed for 2 therapeutic classes-low-sedating antihistamines (LSAs) and nasal steroids (NSs) - were examined 1 year prior to and 1 year after copayment increase. Relative price effects were measured as arc price elasticity, the ratio of the percent change in prescription utilization over the percent change in price, an indicator of how responsive patients are to the copayment increase.

RESULTS: Of 8,643 continuously enrolled health plan beneficiaries, 2,150 patients $(24.8 \%)$ received at least 1 NS or LSA during the 2-year period of the study, from January 1, 1998, through December 31, 1999. An average $\$ 10$ increase in copayment per prescription was associated with no statistically significant change in utilization of combined LSA and NS prescriptions, 2.89 per patient in 1998 and 2.94 in $1999(P=0.597)$. Health plan costs for study drugs, unadjusted for inflation, decreased by $16.3 \%$ from $\$ 86.86$ per patient in 1998 to $\$ 72.68$ in 1999 $(P=0.004)$. Health plan costs per patient per month (PPPM) for all drugs for the 2,150 allergic rhinitis patients decreased by $13 \%$ from \$41.33 PPPM in 1998 to $\$ 35.93$ in $1999(P<0.001)$, and health plan drug costs for all 8,643 members decreased by $13 \%$ from $\$ 14.93$ per member per month (PMPM) in 1998 to $\$ 12.99$ in $1999(P<0.001)$. The actual average copayment increase was $\$ 7.23$ (a $41 \%$ increase) for LSAs, which was associated with a $14.8 \%$ increase in utilization of LSAs and an $11.8 \%$ increase in the number of patients using LSAs; the number of LSA prescriptions per patient per year was unchanged at 2.68 in 1999 versus 2.61 in $1998(P=0.429)$. The actual average copayment increase was $\$ 10.98(71 \%)$ for NSs, which was associated with an $11.3 \%$ decrease in utilization of NSs and a $10.2 \%$ decrease in the number of users of nasals steroids in 1999; the number of nasal steroid prescriptions per patient per year was unchanged at 2.05 in 1999 versus 2.07 in $1998(P=.842)$. The combined utilization of LSA and NS prescriptions increased by $8.9 \%$ following the increase in copayments for these 2 therapeutically interchangeable drugs for allergic rhinitis. LSA prescriptions were less elastic, with an unadjusted arc elasticity of 0.39 , while nasal steroid prescriptions were more responsive to the copayment change, with an unadjusted arc elasticity of -0.22 .

CONCLUSIONS: An average $\$ 10$ increase in patient cost sharing per prescription (46.9\% copayment increase) was associated with an increase in combined utilization of 2 drug classes used for allergic rhinitis (LSAs and NSs) but no change in the number of prescriptions per patient. Health plan costs decreased significantly for allergic rhinitis drugs, all drugs used by allergic rhinitis patients, and all drugs used by continuously enrolled health plan members. NSs exhibited a greater arc price elasticity compared with low-sedating oral antihistamines.

KEYWORDS: Prescription copayment, Utilization, Elasticity, Allergic rhinitis

J Manag Care Pharm. 2004;10(3):226-233
$\mathrm{H}$ ealth care administrators are struggling to provide quality care while controlling costs. New advancements in the treatment of highly prevalent diseases contributed to the $\$ 1.2$ trillion spent on health care in the United States in 1999. ${ }^{1}$ Moreover, during 1999, the growth in prescription drug expenditure led all other health care services, at 16.9\%. ${ }^{1}$ The Centers for Medicare \& Medicaid Studies (CMS) projected that by 2010 , health care expenditure will total $\$ 2.6$ trillion and account for $15.9 \%$ of the gross domestic product. ${ }^{2}$ These increases are fueled in part by the rising drug cost and increased utilization of pharmaceuticals. ${ }^{1,2}$

The increase in pharmacy expenditure can be attributed to a number of factors. For instance, over the past 30 years, the number of third parties expanding prescription benefits has increased, as evidenced by the decrease in the average percentage of prescription costs paid out-of-pocket by the consumer. Based on national estimates from CMS, 96.2\% of medication costs were paid out-of-pocket (cash purchases) by consumers in 1960 compared with 26.6\% in 1998. ${ }^{3}$ Expanding coverage of prescription drugs lowers the effective price to the patient and may lead to increased utilization. ${ }^{4}$ Also, as medical knowledge grows, newer, more expensive pharmaceutical agents are becoming the "standard of care" for more illnesses. Furthermore, there has been an increase in the number of diseases treated with multiple drug therapies, and, as a result of improved medical technology, life expectancy is being extended, allowing patients to utilize medications for longer periods of time. ${ }^{5,6}$ Many other factors, including direct-to-consumer advertising, can also be associated with an increase in prescription drug

\section{Authors}

BRIAN L. MEISSNER, PharmD, is a graduate student and C.E. REEDER, PhD, is a professor, College of Pharmacy, Department of Pharmaceutical and Health Outcomes Sciences, University of South Carolina, Columbia; W. MARK MOORE, PharmD, MBA, is director of admissions, Campbell University, Buies Creek, North Carolina; JUDITH A. SHINOGLE, PhD, MSc, is an assistant professor, College of Pharmacy, Department of Pharmaceutical and Health Outcomes Sciences, School of Public Health, Department of Health Administration, University of South Carolina, Columbia; JOHN M. LITTLE, Jr., MD, is vice president for managed care services, Companion HealthCare, Columbia, South Carolina.

AUTHOR CORRESPONDENCE: Brian L. Meissner, PharmD, College of Pharmacy, Department of Pharmaceutical and Health Outcomes Sciences, University of South Carolina, 1425 Richland St., Columbia, SC 29201.

Tel: (215) 431-7447; Fax: (803) 777-2820; E-mail: meissner@cop.sc.edu

Copyright $@ 2004$, Academy of Managed Care Pharmacy. All rights reserved. 
expenditure. ${ }^{5,7,8}$ In addition to increased utilization of pharmaceuticals, the use of higher-priced brand-name drugs has contributed to rising pharmacy expenditure when these are substituted for older, lower-cost products., ${ }^{910}$ Included in this latter group are the low-sedating antihistamines (LSAs), which ranked sixth in total expenditure by class of medications in $1997 .{ }^{11}$

Double-digit increases in pharmacy expenditure have motivated health plan administrators to pursue alternative methods to control costs. As a result, pharmacy benefits have been modified to include higher prescription copayments and policies to manage the use of preferred drugs through closed and multi-tier formularies, prior authorization, generic substitution, and therapeutic interchange. ${ }^{9,12-15}$ CMS estimated that out-of-pocket expenditure for prescription drugs increased from $\$ 26.3$ billion in 1994 to $\$ 43.1$ billion in $2001 .^{16}$ These increased costs are being shifted to the consumer in the form of higher cost-sharing provisions. Copayments, deductibles, and coinsurance require the patient to pay a certain amount of money to obtain prescriptions covered by the drug benefit. ${ }^{14,17}$ Copayments represent a fixed charge that must be paid for each prescription and are typically not related to the full price of the prescription. Copayments may place the patient in a state of uncertainty where they must decide if the benefits from the drug outweigh the cost (copayment) of purchasing the prescription. When the perceived marginal benefit of the medication is less than the copayment (marginal cost), the patient will not purchase the prescription.

Price elasticity is a measure of consumer responsiveness to price changes. In a competitive market, an elastic demand will be seen if utilization decreases after a small increase in the copayment (i.e., the absolute price elasticity is greater than 1). An elastic demand depends on many factors, including the availability of viable therapeutic alternatives and consumer preferences. For example, a drug class such as the beta-adrenergic blockers would likely have an elastic demand given the abundance of generically and therapeutically equivalent alternatives. However, there are instances in which the demand is inelastic or does not change appreciably with a change in copayment, such as the demand that would be expected for HIV antivirals or chemotherapy medications. ${ }^{18}$

A limited number of studies have assessed the impact of increased patient cost sharing on prescription utilization or expenditure. Results from these studies are mixed. Variations in study designs and differences among patient populations make generalizations difficult. Harris et al. ${ }^{19}$ used a longitudinal cohort to study the impact of increasing copayments from zero to $\$ 1.50$ and $\$ 3.00$ in a staff model health maintenance organization (HMO) in the late 1980s. As part of the analysis, drugs were stratified into essential and discretionary use classifications. The authors reported an overall reduction in prescription demand from $10 \%$ to $12 \%$ among the copayment tiers. More specifically, they noted a much greater decline in drugs categorized as discretionary compared with drugs defined as essential. In addition, after controlling for potential confounders, they found that a $\$ 3$ copayment was associated with a 13\% decrease in use of essential drugs compared to a zero copayment.

Soumerai et al..$^{20}$ assessed the impact of prescription quantity limitations on drug utilization in a New Hampshire Medicaid population. Using 3 classification systems (effective-essential medication; effective-nonessential; and nonessential, symptomatic-relief medications), this study assessed prescription use following the transition from a no-prescription limit to a 3-prescription limit and from a 3-prescription limit to a $\$ 1$ prescription copayment without a prescription limit. Multivariate analysis indicated that the 3-prescription limit was associated with decreased use of both essential and nonessential medications. After instituting a \$1 copayment, prescription utilization increased to just below the levels prior to the imposition of the quantity limits.

Johnson et al. ${ }^{21}$ analyzed the impact of prescription utilization within a Medicare population after copayment increases and stratified the analysis by drug classes. This study used a combination of matching, random-sample generation, and multivariate models to control for potential confounders. Results indicated that after the copayment increased, prescription utilization for self-limiting and chronic disease states did not change.

In 1983 , Nelson et al..$^{22}$ compared the impact of a $\$ .50$ copayment increase within the South Carolina Medicaid population with a control cohort (Tennessee Medicaid) using ordinary least squares to control for confounders. The results indicated an overall decrease in prescription utilization. They also demonstrated a lower average monthly expenditure after instituting a prescription copayment. Using these same data, Reeder and Nelson ${ }^{23}$ (1985) examined the effect of the copayment change within 10 therapeutic categories and found a differential effect among therapeutic categories. Little change in monthly expenditure occurred in the drug therapy groups-analgesics and hypnotics_-while the cardiovascular, diuretic, and psychotherapeutic drug groups had significant declines in both the level and growth (slopes) of monthly expenditure after copayment increase. While this study is only generalizable to the Medicaid population and examined a small change in cost sharing, it did highlight that an increase in patient copayments for prescription drugs may have a differential effect among therapeutic categories. And yet, few present-day studies have examined the effects of increased cost sharing within therapeutic categories of drugs.

Joyce et al. ${ }^{6}$ studied the impact of an increased prescription copayment within multiple formulary designs (1-tier, 2-tier, and 3-tier) using claims from a working population and its beneficiaries aged 18 to 64 years. A 2-part probit model was used to examine the impact on the provider and patients. The results indicated that the average annual decrease in drug cost per member ranged from $22.3 \%(P<0.001)$ to $32.9 \%(P<0.001)$, depending on formulary design. In addition, out-of-pocket costs increased from $17.6 \%$ to $25.6 \%$ after doubling the copayment within a 2-tier drug plan. Thus, the magnitude of drug 


\section{TABLE 1 Prescription Utilization and Copays for Low-Sedating} Antihistamines and Nasal Steroids for 1998 and 1999

\begin{tabular}{|c|c|c|c|c|}
\hline \multirow{2}{*}{$\begin{array}{l}\text { Drug } \\
\text { Low-Sedating Antihistamines (LSA) }\end{array}$} & \multicolumn{2}{|c|}{1998} & \multicolumn{2}{|c|}{1999} \\
\hline & Copayment (\$) & Utilization, \% (No.) & Copayment (\$) & Utilization, \% (No.) \\
\hline Loratadine (Claritin) & 15 & $42.1(1,363)$ & 25 & $38.0(1,413)$ \\
\hline Loratadine plus pseudoephedrine (Claritin-D) & 25 & $23.7(767)$ & 25 & $23.3(868)$ \\
\hline Fexofenadine (Allegra) & 15 & $10.0(324)$ & 25 & $10.6(396)$ \\
\hline Fexofenadine pseudoephedrine (Allegra-D) & 25 & $3.5(115)$ & 25 & $7.5(279)$ \\
\hline$\overline{\text { Cetirizine (Zyrtec) }}$ & 15 & $20.7(672)$ & 25 & $20.6(765)$ \\
\hline Total & & $100(3,241)$ & & $100(3,721)$ \\
\hline \multicolumn{5}{|l|}{ Nasal Steroids (NS) } \\
\hline Flunisolide (Nasalide, Nasarel) & 25 & $4.0(38)$ & 35 & $6.5(55)$ \\
\hline Budesonide (Rhinocort) & 15 & $8.9(85)$ & 25 & $9.1(77)$ \\
\hline Fluticasone (Flonase) & 15 & $45.4(435)$ & 25 & $49.7(422)$ \\
\hline Triamcinolone (Nasacort, Nasacort AQ) & 15 & $8.3(79)$ & 35 & $9.9(84)$ \\
\hline $\begin{array}{l}\text { Beclomethasone (Beconase, Beconase AQ, } \\
\text { Vancenase, Vancenase AQ Vancenase AQ DS) }\end{array}$ & 15 & $33.4(320)$ & 25 & $24.8(211)$ \\
\hline$\overline{\text { Total }}$ & & $100(957)$ & & $100(849)$ \\
\hline
\end{tabular}

cost savings exceeded the magnitude of increase in copayments for the 2-tier plan.

A few studies have assessed the impact of insurance coverage on the demand for pharmaceuticals. Using data from the RAND Health Insurance Experiment, Leibowitz et al., ${ }^{4}$ assessed the effects of copayment on prescription utilization. They found that patients randomized to more generous insurance plans (richer benefits) utilized more medications. This finding is theoretically consistent with a change in quantity demanded following a change in price. Coulson et al. ${ }^{24}$ analyzed the impact of various types of insurance coverage and access to care on prescription utilization. They used both instrumental variables to control for unobserved heterogeneity and a Heckman 2-stage model to address selection issues common in administrative claims datasets. The results indicated that patients with medical or prescription drug coverage (insurance) consume, on average, more prescriptions than do patients with limited physician access or drug coverage.

In summary, all of these studies measured the effects of relatively small increases in prescription copayment. Additionally, very few studies assessed utilization by individual drug therapy class. The majority of prior research was performed within a Medicaid or other public drug plan, which limits the generalizability of the findings. To address some of these limitations, we investigated the impact of a $\$ 10$ copayment increase within a working population of a public employer with health benefits administered by a private, for-profit managed care organization.

\section{Methods}

This study examined drug utilization of LSAs and nasal steroids (NSs) 1-year prior to a copayment increase (January 1, 1998, to
December 31, 1998) and 1-year after the copayment increase (January 1, 1999, to December 31, 1999). Data were extracted from a pharmacy claims database for a public employer with health benefits administered by a private, for-profit, network model HMO with a total of approximately 130,000 lives, located in the southeastern United States. Of the 130,000 lives, a total of approximately 15,000 beneficiaries are enrolled in a single health plan funded by a large public employer. This analysis was further limited to select nonfederal employer segments within this health plan. The study inclusion criteria were members from (a) select groups covered by the single large nonfederal public employer who (b) had a pharmacy claim in 1998 or 1999 for either an LSA or an NS and (c) were enrolled continuously in the HMO for the 2-year period from January 1, 1998, to December 31, 1999. A mail-service pharmacy benefit was not provided to health plan members during the study period.

Prior to January 1, 1999, copayments were $\$ 5$ for each for generic prescription, $\$ 15$ for a prescription for a preferred drug, and $\$ 25$ for nonpreferred drugs, for a maximum 30-day supply of the prescription. On January 1, 1999, copayments rose to $\$ 10$ for generic drugs, $\$ 25$ for preferred drugs, and $\$ 35$ for nonpreferred drugs, each for a maximum 30-day supply prescription for all beneficiaries from the single large employer group enrolled in the HMO. This copayment increase represents relative price increases of $100 \%, 67 \%$, and $40 \%$, respectively, for the 3 tiers. If the full price of the prescription was below the copayment amount, patients were charged the lower price. For example, if a patient received a prescription for nine $10 \mathrm{mg}$ tablets of a "preferred drug" during 1999 and the price was $\$ 19$, the patient would pay the lesser of the 2 amounts ( $\$ 19$ versus $\$ 25)$. 
Concurrent with copayment changes, formulary status for certain drugs was modified. From 1998 to 1999, the formulary status for loratadine plus pseudoephedrine (Claritin-D) and fexofenadine plus pseudoephedrine (Allegra-D) was changed from nonpreferred to preferred; the single agent formulation of each, loratadine or fexofenadine, remained preferred (tier-2 copay) drugs throughout the 2-year period. In addition, triamcinolone nasal spray was converted from preferred status in 1998 to nonpreferred (tier-3 copay) status in 1999. The changes in formulary status of these 3 agents accounted for less than $24 \%$ of the overall prescription utilization for LSAs and NSs combined (Table 1). Nonetheless, a subanalysis was conducted, excluding those medications that changed formulary status, to assure minimal influence on overall results.

LSAs included in the analysis were the brand-name products for loratadine (Claritin), loratadine plus pseudoephedrine (Claritin-D), fexofenadine (Allegra), fexofenadine plus pseudoephedrine (Allegra-D), and cetirizine (Zyrtec). NSs were included in this analysis since they are considered reasonable therapeutic alternatives for LSAs and included the brand-name products for flunisolide, budesonide, fluticasone, triamcinolone, and beclomethasone. ${ }^{25}$ The data were also combined for the entire cohort to assess the overall effect of the copay change between 1998 and 1999. Cost was defined as the amount of money paid (including a dispensing fee) by the health plan to the pharmacy for each prescription dispensed before consideration of member cost-share.

A 2-sample $t$ test was used to assess differences after the copayment increase and across therapeutic categories for the following variables: mean age, mean prescriptions per patient per month (PPPM), and mean number of study prescriptions PPPM. A chi-square test was used to assess gender differences between therapeutic groups and the percent of new versus refill prescriptions within the 2 groups after copayment increase. A paired $t$ test was used to test differences between the mean number of prescriptions dispensed per year (study drug), mean drug costs per patient (both study drug and all other drugs for allergic rhinitis patients), and PPPM (all drugs for allergic rhinitis patients) drug costs, mean copayments, and the per-member-per-month (PMPM) cost to the health plan. A 2-tailed significance level of 0.05 was used to determine statistical significance. Data management and statistical analyses were performed using SAS (Cary, North Carolina) version 8.0. ${ }^{26}$

\section{Results}

Of the approximately 15,000 members enrolled in the single large public employer health plan, 8,643 nonfederal members were continuously enrolled from January 1, 1998, to December 31,1999 . A total of 2,150 patients ( $24.8 \%$ of continuously eligible members) received either 1 or more prescriptions for an LSA $(\mathrm{N}=1,931)$ and/or an NS $(\mathrm{N}=688)$ during the 2 years (Table 2$)$; a total of 469 patients (5.4\% of eligible members and $21.8 \%$ of

\begin{tabular}{|c|c|c|c|}
\hline & $\begin{array}{l}\text { Low-Sedating } \\
\text { Antihistamines }\end{array}$ & $\begin{array}{l}\text { Nasal } \\
\text { Steroids }\end{array}$ & $P$ Value \\
\hline Number of patients* & 1,931 & 688 & - \\
\hline Age (SD) & $38.3(16.0)$ & $39.8(15.2)$ & 0.102 \\
\hline Female (\%) & $1,372(71.0)$ & $459(66.7)$ & 0.033 \\
\hline Male (\%) & $559(28.9)$ & $229(33.2)$ & \\
\hline Total number of Rxs dispensed $\dagger$ & 76,004 & 32,198 & - \\
\hline Mean Rxs PPPM $\dagger(S D)$ & $1.64(1.55)$ & $1.95(1.76)$ & $<0.001$ \\
\hline $\begin{array}{l}\text { Number of study Rxs dispensed } \ddagger \\
\text { (\% of total) }\end{array}$ & $6,962(9.1)$ & $1,806(5.6)$ & - \\
\hline Mean study Rxs PPPM $¥(S D)$ & $0.15(0.18)$ & $0.11(0.12)$ & $<0.001$ \\
\hline \multicolumn{4}{|c|}{$\begin{array}{l}\text { * A total of } 469 \text { patients had both a low-sedating antihistamine and nasal steroid } \\
\text { prescription dispensed during the 2-year period. } \\
+ \text { This value includes all prescriptions dispensed for this population (study and non- } \\
\text { study drugs), per patient per month (PPPM). } \\
\text { \# This value includes only low sedating antihistamines or nasal steroid prescrip- } \\
\text { tions. }\end{array}$} \\
\hline
\end{tabular}

allergic rhinitis patients who received pharmacotherapy with LSAs or NSs received at least 1 LSA and 1 NS during the 2-year study period. The number of patients who received an LSA or NS increased from 1,451 (16.8\% of eligible members) in 1998 to 1,553 (18.0\% of eligible members) in 1999. The mean age for patients receiving an NS was 39.8 years compared with 38.3 years for patients receiving LSAs $(P=0.10)$. Females comprised approximately $71 \%$ of patients who received a prescription for an LSA compared with almost $67 \%$ of patients who received NSs during the 2-year study period $(P=0.03)$.

The mean number of all prescriptions (study and nonstudy medications) dispensed PPPM was higher for patients who received an NS prescription than patients who received an LSA prescription (1.95 prescriptions PPPM versus 1.64 prescriptions PPPM; $P<0.0001)$. On average, more LSA prescriptions PPPM were dispensed than NSs (0.15 LSA prescriptions PPPM versus 0.11 NS prescriptions PPPM; $P<0.0001$ )

Although the sum total of LSA and NS prescriptions increased $8.9 \%$ after the change in copayment $(4,570$ in 1999 versus 4,198 in 1998), no statistically significant difference was noted for the average number of prescriptions dispensed per patient. The total number of LSA prescriptions dispensed during the 2 years was 6,962 compared with 1,806 NS prescriptions. The number of patients who received an LSA increased by $11.8 \%$ in 1999 (Table 3), the year in which there was a $41.1 \%$ increase in the average copayment amount (Table 4). The number of patients who received an NS prescription declined by $10.2 \%$ (Table 3) in 1999 , following the average $71.3 \%$ increase in the average copayment amount (Table 4). The number of prescriptions increased by $14.8 \%$ for LSAs in 1999, but the number of NS prescription claims decreased by $11.3 \%$. Total prescriptions for allergic 
TABLE 3 Utilization and Drug Costs for Low-Sedating Antihistamines (LSA) and Nasal Steroids (NS) for Preperiod (1998) Versus Postperiod (1999) for Allergic Rhinitis Patients

\begin{tabular}{|c|c|c|c|c|c|c|c|c|c|}
\hline Study Drugs & LSA 1998 & LSA 1999 & $P$ Value & NS 1998 & NS 1999 & $P$ Value & LSA/NS 1998 & LSA/NS 1999 & $P$ Value \\
\hline$\overline{\text { Patients (n) }}$ & $1,242 *$ & $1,389 *$ & - & $462^{\dagger}$ & $415^{\dagger}$ & - & $1,451^{\ddagger}$ & $1,553^{\ddagger}$ & - \\
\hline Total Rxs & 3,241 & 3,721 & - & 957 & 849 & - & 4,198 & 4,570 & - \\
\hline Rxs per patient & 2.61 & 2.68 & $0.429^{\dagger \dagger}$ & 2.07 & 2.05 & $0.842^{\dagger \dagger}$ & 2.89 & 2.94 & $0.597^{\dagger \dagger}$ \\
\hline $\operatorname{Plan}_{\text {cost }}{ }^{\S \|}$ & $\$ 102,524$ & $\$ 99,639$ & - & $\$ 23,523$ & $\$ 13,245$ & - & $\$ 126,048$ & $\$ 112,884$ & - \\
\hline $\begin{array}{l}\text { Plan cost per } \\
\text { patient } \|, \#\end{array}$ & $\$ 82.54$ & $\$ 71.73$ & $0.385^{\dagger \dagger}$ & $\$ 50.91$ & $\$ 31.91$ & $<0.001$ & $\$ 86.86$ & $\$ 72.68$ & 0.004 \\
\hline \multicolumn{10}{|c|}{ All Drugs for Allergic Rhinitis Patients } \\
\hline Plan cost 11,9 & $\$ 487,211$ & $\$ 484,538$ & - & $\$ 232,681$ & $\$ 185,056$ & - & $\$ 719,892$ & $\$ 669,594$ & - \\
\hline $\begin{array}{l}\text { Plan cost per } \\
\text { patient** }\end{array}$ & $\$ 392$ & $\$ 348$ & $<0.001^{\dagger \dagger}$ & $\$ 503$ & $\$ 445$ & $0.001^{\dagger \dagger}$ & $\$ 496$ & $\$ 431$ & $<0.001^{\dagger \dagger}$ \\
\hline $\begin{array}{l}\text { Plan cost } \\
\text { PPPM }^{\|}(S D)\end{array}$ & $\begin{array}{l}\$ 32.69 \\
(44.68)\end{array}$ & $\begin{array}{l}\$ 29.07 \\
(48.70)\end{array}$ & $<0.001^{\dagger \dagger}$ & $\begin{array}{l}\$ 41.97 \\
(51.87)\end{array}$ & $\begin{array}{l}\$ 37.16 \\
(56.13)\end{array}$ & $0.001^{\dagger \dagger}$ & $\$ 41.33$ & $\$ 35.93$ & $<0.001^{\dagger \dagger}$ \\
\hline
\end{tabular}

* A total of 698 patients received a low-sedating antihistamine in both 1998 and 1999

+ A total of 189 patients received a nasal steroid in both 1998 and 1999.

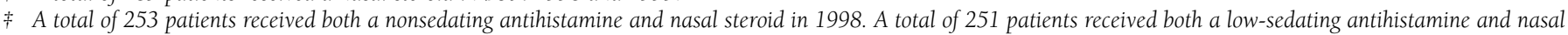
steroid in 1999. A total of 854 patients received a nasal steroid and/or low-sedating antihistamine in 1998 and 1999.

$\S$ The total cost of the study (LSA and NS) drugs.

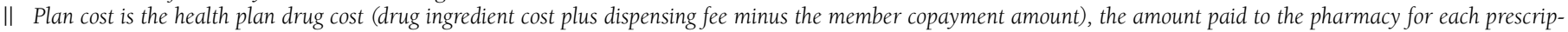
tion dispensed and expressed as cost per patient per month (PPPM).

II The total plan cost of all drugs for patients on 1 or more study drugs (i.e., not just NS and LSA).

\# The health plan cost for all study (NS and LSA) drugs, per patient.

** The average cost of all medications per individual on a study drug (NS and LSA).

t† Paired t test.

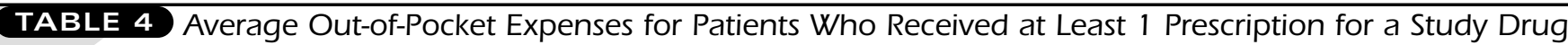

\begin{tabular}{l|c|c|c|c|c|c|c}
\hline Year & 1998 & 1999 & & 1998 & 1999 & \\
\hline Drug Class & No. Rxs & No. Rxs & \% Change & Mean Copayment (SD) & Mean Copayment (SD) & \% Change & $P$ Value \\
\hline Low-sedating antihistamines & 3,241 & 3,721 & 14.8 & $\$ 17.59(4.37)$ & $\$ 24.82(1.24)$ & 41.1 & $<0.001$ \\
\hline Nasal steroids & 957 & 849 & -11.3 & $\$ 15.39(1.95)$ & $\$ 26.37(4.30)$ & 71.3 & $<0.001$ \\
\hline Total for allergic rhinitis & 4,198 & 4,570 & 8.9 & $\$ 17.09(4.06)$ & $\$ 25.11(2.23)$ & 46.9 & $<0.001$ \\
\hline
\end{tabular}

rhinitis (LSA plus NS) increased by $8.8 \%$ after the $\$ 8.02$ (46.9\%) average increase in copayment in 1999.

The average $46.9 \%$ increase in out-of-pocket expense for prescriptions for allergic rhinitis patients from 1998 to 1999 was associated with a 13\% decrease in the total PMPM drug cost for this continuously enrolled group, from $\$ 14.93$ in 1998 to $\$ 12.99$ in $1999(P<0.001)$ (Table 5). In comparison, the national increase in out-of-pocket expenses rose 31\% (\$15.57 in 1998 versus \$22.61 in 1999) for all prescriptions from 1998 to 1999. ${ }^{27,28}$ The total drug cost PPPM for allergic rhinitis patients (NS or LSA) decreased from $\$ 41.33$ in 1998 to $\$ 35.93$ in 1999 $(P<0.0001)$. The PPPM cost decreased similarly by $11.4 \%$ ( $\$ 41.97$ in 1998 versus $\$ 37.16$ in $1999, P=0.0010$ ) and $11.1 \%$ ( $\$ 32.69$ in 1998 versus $\$ 29.07$ in $1999, P<0.0001$ ) for the NS and LSA cohorts, respectively.
As noted in the methods section, the formulary status (and copayment) changed from nonpreferred status to preferred status for loratadine plus pseudoephedrine and fexofenadine plus pseudoephedrine. Despite this change, utilization of LSAs and NSs remained consistent throughout the 2-year study period. The subanalysis, which excluded those medications that changed formulary status, indicated that the total number of LSA prescriptions increased by 9\% (2,359 in 1998 versus 2,574 in 1999). In contrast, the total number of NS prescriptions decreased by 12\% (878 in 1998 versus 765 in 1999), which resulted in a total increase of 3.1\% (3,237 in 1998 versus 3,339 in 1999) for the combined cohort. The number of prescriptions per patient for the combined group was 2.89 in 1998 as compared with 2.94 in 1999, which was not statistically significant. Similarly the mean copayment increased by $65 \%$ ( $\$ 14.96$ in 
1998, $\$ 24.81$ in 1999; $P<0.0001)$ in the LSA cohort and 64\% ( $\$ 15.43$ in $1998, \$ 25.42$ in $1999 ; P<0.0001$ ) in the NS group.

The unadjusted arc elasticities for both drug classes were calculated. (The elasticities are the ratio of the percent change in prescriptions over the percent change in price.

$$
\text { Arc elasticity can be calculated as } \frac{\left(Q_{2}-Q_{1}\right) /\left(Q_{2}+Q_{1}\right)}{\left(P_{2}-P_{1}\right) /\left(P_{2}+P_{1}\right)}
$$

Those estimated in this paper have not been adjusted for potential cofounders such as age, gender, etc.) These arc elasticities indicate the population change in prescription utilization given the increase in out-of-pocket expense. If demand is elastic (price sensitive), a given increase in price will be associated with a smaller expenditure. Similarly, if demand is inelastic (price insensitive), a price increase will be associated with greater expenditure. LSAs were less price sensitive, with an arc elasticity of 0.39 , while NSs were more responsive to the copayment change, with an arc elasticity of -0.22 .

\section{Discussion}

The $\$ 10$ estimated ( $\$ 8.02$ actual) average increase in prescription copayment appeared to have no effect on the combined utilization measures for these 2 principal drug categories for allergic rhinitis, although the $14.8 \%$ increase in LSA utilization overshadowed the $11.3 \%$ decrease in NS use. The results also indicated more price sensitivity for NS users compared with LSA users after the copayment increase. The overall PMPM and PPPM drug plan costs declined, which can be attributed to the increase in patient out-of-pocket expenses.

Health plan PMPM and PPPM drug costs, unadjusted for inflation, decreased by $\$ 1.94$ (13\%) and $\$ 5.40$ (13\%), respectively, after the copayment increase took effect January 1, 1999. These cost reductions would have been larger if adjusted for inflation in prescription drugs in 1999. Patient cost sharing did not affect utilization to the same extent in the 2 drug classes since utilization of LSAs increased by $14.8 \%$ and NS utilization decreased by $11.3 \%$. These differences in utilization can be attributed in part to an $11.8 \%$ increase in the number of patients receiving an LSA compared with a $10.2 \%$ decrease in the number of NS users. Nonetheless, these findings are consistent with several other studies that compared medication utilization by therapeutic drug class and emphasize the need to examine, separately, therapeutic classes when assessing drug utilization after price changes. ${ }^{19-21}$ The differences in utilization between therapeutic alternatives need to be quantified to assist decision makers in designing drug formularies that reduce inappropriate or unnecessary drug use while realizing the benefits of appropriate medication use.

Although the percentage of patients using LSAs or NSs appears to be relatively high (24.8\%) compared with other published estimates, the number of prescriptions per 1,000 members is similar to that of other reports. The 2001 Novartis

\begin{tabular}{|c|c|c|c|}
\hline \multicolumn{4}{|c|}{$\begin{array}{l}\text { TABLE } 5 \text { Drug Costs Per Member } \\
\text { Per Month for All Members* }\end{array}$} \\
\hline & 1998 & 1999 & $P$ Value \\
\hline Eligible members & 8,643 & 8,643 & - \\
\hline Total drug cost & $\$ 1,548,479$ & $\$ 1,347,270$ & - \\
\hline PMPM cost (SD) & $\$ 14.93(40.2)$ & $\$ 12.99(41.4)$ & $<0.001$ \\
\hline
\end{tabular}

Pharmacy Benefit Report ${ }^{29}$ estimated that 390 LSA prescriptions were dispensed per 1,000 members (0.0325 Rxs PMPM), which is consistent with our range of 374 (0.031 Rxs PMPM in 1998) to 430 (0.036 Rxs PMPM in 1999) antihistamine prescriptions per 1,000 members. In our study, almost $70 \%$ of the patients received only 1 or 2 LSA prescriptions during the 2-year study period. It is also important to note that the study population consisted of relatively high pharmacy benefit users, considering the LSA prescriptions accounted for only $9.1 \%$ of total prescriptions for LSA patients and 5.6\% of total prescriptions for the NS patients.

\section{Limitations}

One of the several assumptions required to perform a 2-sample $t$ test is that the 2 samples are independent. Violation of this assumption may produce biased estimates. This analysis violated the assumption when a 2-sample $t$ test was used since patients may have either been receiving both an LSA or NS drug concomitantly. As a result, our $P$ values for the mean age, mean prescriptions PPPM, and mean number of study prescriptions PPPM should be interpreted with caution. In contrast, a paired $t$ test was used to test the differences between PPPM costs, which generated a more conservative $P$ value estimate. Nevertheless, these findings were statistically significant and consistent with other studies that assessed the impact of an increased prescription copayment. ${ }^{17,30}$

Our study did not have a control group, and while there appears to be an association between changes in copayment and utilization, no causality can be inferred given our study design. The arc price elasticity estimates have not been adjusted for potential confounders such as age, gender, income level, disease severity, and self-selection since the objective was more descriptive in nature. However, work is being done to develop more robust multivariate models. It is also important to note that it is not possible to assess the price elasticity in the presence of an overall increase of all drugs without examining cross-price elasticities. A current research project is addressing this issue. These limitations make extrapolation of these results into public health policy difficult. It was not possible to control for any clinical treatment changes that may have altered prescribing 
patterns for the medications under study.

The formulary status for loratadine plus pseudoephedrine and fexofenadine plus pseudoephedrine was changed from nonpreferred in 1998 to preferred in 1999. This had the effect of negating the increase in copayment that affected other drugs in this study since these 2 drugs had the same copayment in 1999 as in the prior year. However, it appears, based on the subanalysis, that this change did not have a significant impact on the number of additional prescriptions utilized or mean copayments in 1999 compared with 1998.

To more fully understand the impact on prescription costsharing changes, it is necessary to evaluate the impact of additional health care use in the form of emergency room visits and physician visits. ${ }^{31}$ Such analyses will allow policy makers to structure a prescription drug benefit that is efficient and effective for both the managed care organization and the patient.

\section{Conclusions}

This study provides preliminary findings that health plan drug costs per member and per patient declined significantly when the prescription copayment per month (30-day supply) is increased by an average of $\$ 10$. No change in utilization of LSAs and NSs as measured by the number of prescriptions per patient was observed when the average actual copayment per prescription increased by $\$ 7.23$ and $\$ 10.98$, respectively. However, there was a significantly different outcome in utilization between these 2 drug classes used to treat allergic rhinitis. The number of patients who used an LSA increased by $11.8 \%$ in the year following the copayment increase while the number of patients who used an NS decreased by $10.2 \%$; the number of prescriptions for LSAs increased by $14.8 \%$ in the year following the copayment increase while the number of prescriptions for NSs decreased by $11.3 \%$; the net changes in LSAs per patient, NSs per patient, and combined LSA/NS prescriptions per patient were insignificant. In terms of price sensitivity, the arc price elasticity differed between the 2 therapeutic classes $(0.39$ for LSA prescriptions and -0.22 for NS prescriptions). Further study is needed to assess the cumulative price elasticity following an increase in copayment within individual drug classes.

\section{DISCLOSURES}

No outside funding supported this research. Author Brian L. Meissner served as principal author of the study. Study concept and design were contributed by Meissner and authors W. Mark Moore, Judith A. Shinogle, C.E. Reeder, and John M. Little, Jr. Analysis and interpretation of data were contributed by Meissner, Moore, Shinogle, and Reeder. Drafting of the manuscript was the work of all authors, and its critical revision was the work of Meissner, Shinogle, and Reeder. Statistical expertise was contributed by Meissner and Shinogle.

\section{REFERENCES}

1. Health Care Financing Administration, Office of the Actuary, National Health Statistics Group. National health expenditures, aggregate amounts, and average annual percentage change, by type of expenditure: years 1960-1999. Available at: www.cms.hhs.gov/review/01summer/01Summerpg77.pdf. Accessed May 9, 2001

2. Health Care Financing Administration. National health expenditures projections: 2000-2010. Available at: www.cms.hhs.gov/statistics/nhe/historical/t2.asp. Accessed September 9, 2001.

3. Danzon PM, Pauly MV. Insurance and new technology: from hospital to drugstore. Health Aff. 2001;20:86-1000.

4. Leibowitz A, Manning WG, Newhouse JP. The demand for prescription drugs as a function of cost-sharing. Soc Sci Med. 1985;21(10):1063-69.

5. Mehl B, Santell J. Projecting future drug expenditures-2001. Am J Health Syst Pharm. 2001;58:125-33

6. Joyce GF, Escace JJ, Solomon MD, Goldman DP. Employer drug benefit plans and spending on prescription drugs. JAMA. 2002;288(14):1733-39.

7. Rosenthal MB, Berndt ER, Donohue JM, Epstein, AM, Frank, RG. Demand effects of recent changes in prescription drug promotion. Available at: www.kff.org/rxdrugs/6085-index.cfm. Accessed July 9, 2003.

8. Increase in drug expenditures tied to more prescriptions, costlier brandname products. Am J Health Syst Pharm. 2001;58:1089,1093.

9. Mehl B, Santell J. Projecting future drug expenditures—2000. Am J Health Syst Pharm. 2000;57(2):129-38.

10. Mullins DC, Wang J, Palumbo FB, et al. The impact of pipeline drugs on drug spending growth. Health Aff. 2001;20(3):210-15.

11. Benedetto SR, Sloan AS, Duncan DS. Impact of interventions designed to increase market share and prescribing of fexofenadine at HMOs. Am J Health Syst Pharm. 2000;57(19):1778-85.

12. Litton LM, Sisk FA, Akins ME. Managing drug costs: The perception of managed care pharmacy directors. Am J Manag Care. 2000;6(7):805-14.

13. Lyles A, Palumbo FB. The effect of managed care on prescription drug costs and benefits. Pharmacoeconomics. 1999;15(2):129-40.

14. Hurley J, Johnson NA. The effects of copayment within drug reimbursement programs. Can Pub Pol. 1991;4:473-89.

15. Motheral BR, Henderson R. The effect of a closed formulary on prescription drug use and costs. Inquiry. 1999;36:481-91.

16. Health Care Financing Administration. National health expenditures Available at: http://www.cms.hhs.gov/statistics/nhe/historical/tables.pdf. Accessed July 15, 2003.

17. Motheral BR, Henderson R. The effect of copay increase on pharmaceutical utilization, expenditures, and treatment continuation. Am J Manag Care 1999;5(11):1383-94.

18. Jacobs P. The economics of health and medical care. 4th ed. Aspen Publishers. Gaithersburg, MD; 1996.

19. Harris BL, Stergachis A, Ried LD. The effect of drug copayments on utilization and cost of pharmaceuticals in a health maintenance organization. Med Care. 1990;28(10):907-17.

20. Soumerai SB, Avorn J, Ross-Degnan DR, et al. Payment restrictions for prescription drugs under Medicaid. New Engl J Med. 1987;317(9):550-56.

21. Johnson RE, Goodman MJ, Hornbrook MC, et al. The impact of increasing patient prescription drug sharing on therapeutic classes of drugs received and on the health status of elderly HMO members. Health Serv Res. 1997;32(1): 103-22.

22. Nelson AA, Reeder CE, Dickson MW. The effect of a Medicaid drug copayment program on the utilization and cost of prescription services. Med Care. 1984;22(8):724-35.

23. Reeder CE, Nelson AA. The differential impact of copayment on drug use in a Medicaid population. Inquiry. 1985(winter):396-403. 
24. Coulson EN, Stuart BC. Insurance choice and the demand for prescription drugs. SEJ. 1995;61(4):1146-57.

25. Dykewicz MS, Fineman S Skoner DP, et al. Diagnosis and management of rhinitis: complete guidelines of joint task force on practice parameters in allergy, asthma and immunology. Ann Allergy. 1998:81(5, pt 2):478-518.

26. SAS Institute Inc. (1999). Version 8. Cary, NC: SAS Institute Inc.

27. Chao HS. Novartis Medical Benefit Report (annual resource 1998). Totowa, NJ: Emron; 1998

28. Chao HS. Novartis Medical Benefit Report (annual resource 1999).

Totowa, NJ: Emron; 1999
29. Chao HS. Novartis Medical Benefit Report (annual resource 2001) Totowa, NJ: Emron; 2001

30. Motheral B, Fairman KA. Effect of a three-tier copay on pharmaceutical and other medical utilization. Med Care. 2001;39(12):1293-1304.

31. Somerai SB, McLauglin TJ, Ross-Degnan D, et al. Effects of limiting Medicaid drug-reimbursement benefits on the use of psychotropic and acute mental health services by patients with schizophrenia. New Engl J Med. 1994;331(10):650-55. 